\title{
A Photovoltaic System for Heterogeneous Networks: a Technical, Economic and Environmental Analysis
}

\author{
M. A. Souza, F. S. Farias, H. P. Kuribayashi, C. R. L. Francês, J. C. W. A. Costa, and D. L. Cardoso
}

\begin{abstract}
The modern society is daily becoming more internetconnected. Such a connection requires an unprecedented amount of energy to operate each piece of equipment that is part of the heterogeneous networks (HetNets). The network infrastructure is highly energy-consuming and producing a considerable amount of $\mathrm{CO}_{2}$. One strategy to minimize such energy consumption is making usage of renewable energy, such as solar and wind. This article aims to present a study of the technical, economic, and environmental feasibility for the installation of photovoltaic harvesting systems in the context of HetNet and backhaul networks. This proposal is based on the use of analytical models to scale the deployment of the photovoltaic systems, considering costs associated with acquisition, operation, maintenance, and adopted the energy matrix of this system. The results indicate sustainable and financial viability with the adoption of photovoltaic systems when compared with the energy source mainly considered in the literature. Also, the results highlight that adopted energy matrix and environmental parameters are essential items, which must be highly considered when the overall mobile network infrastructure is planned.
\end{abstract}

Index Terms-Environmental analysis, Heterogeneous Networks, Photovoltaic System, Sensitivity Analysis, TechnicalEconomic Evaluation.

\section{INTRODUCTION}

$\mathbf{T}$ HE increasing growth of new users attracted to 4th and 5th generation devices (i.e. 4G and 5G), has been causing a widespread expansion of the infrastructure of telecommunications networks [1]. This expansion has mainly led to a process of densification of heterogeneous networks (HetNets), from first generation $(1 \mathrm{G})$ to $5 \mathrm{G}$, that seeks to ensures a highspeed Internet service at any time and any place [2], through the massive installation of both of the following: i) new Base Stations (BS) that seek to meet the requirements defined by the technical traffic regulations and 2) the new mobile backhaul infrastructure that is responsible for serving as point-to-point or point-to-multipoint data transmission between the BSs and the Central Office (CO) [3]-[5].

M. A. Souza is with the Federal University of Southern and Southeastern Para, Maraba, PA, 68500-080 Brazil. e-mail: marcela.alves@unifesspa.edu.br F. S. Farias is with the Faculty of Information Systems, Federal University of Para, Cameta, PA, 68400-000 Brazil. e-mail: fabriciosf@ufpa.br

H. P. Kuribayashi is with Faculty of Computing and Eletrical Engineering, Federal University of Southern and Southeastern Para, Maraba, PA, 68505-080 Brazil. e-mail: hugo@unifesspa.edu.br

C. R. L. Francês, J. C. W. A. Costa and D. L. Cardoso are with Faculty of Computer Enginering and Telecommunications, Federal University of Para, Belem, PA, 66075-110 Brazil. e-mail: \{rfrances, jweyl, diego\}@ufpa.br.

This study was financed in part by the Coordenação de Aperfeiçoamentode Pessoal de Nível Superior - Brasil (CAPES) - Finance Code 001

Digital Object Identifier: 10.14209/jcis.2020.10
The world economy relies heavily on fossil energies. According to the BP Statistical Review of World Energy, Oil consumption grew by an above-average rate of 1.4 million barrels per day $(b / d)$, or $1.5 \%$, where China $(680,000 b / d)$ and the US $(500,000 \mathrm{~b} / d)$ were the largest contributors to growth [6]. Hence, a part of the energy consumed by the Mobile Network Operators (MNOs) to operate the mobile network infrastructure comes from these traditional and highly-polluting sources [7]. Moreover, energy consumption represents one of the main areas of MNO expenditure [8], [9]. In light of this, new HetNets and the installation of its mobile backhaul infrastructure must be carefully planned. In addition, this high rate of energy consumption leads to an increase in the total greenhouse gas emissions in the atmosphere [10]-[12].

Although the deployment of ICT has rapidly expanded during the past two decades, several governments are now concerned with how to reduce energy consumption and prevent environmental degradation [13]. In fact, a conservative estimate currently attributes around $4 \%$ of all electricity consumption and over $2 \%$ of all $\mathrm{CO}_{2}$ emissions to the application of ICT [14]. A number of research studies have taken account of the related literature in an attempt to reduce energy consumption in ICT [15]. This has involved the use of renewable energy sources [16], [17], making improvements in spectral efficiency [18], [19], the application of energyharvesting techniques [20]-[22], and development of the next generation mobile networks (i.e., 5G, 6G) [23], [24].

Furthermore, [25] suggests that there is a strong relationship between the carbon footprint and the role of ICT in energy consumption. The size of the ICT carbon footprint and its comparison with other sectors has been discussed in several works [25]-[27]. In general, it is assumed that the carbon and energy footprints in the ICT sector are growing fast and are in line with the exponential increase in data traffic. Hence, owing to these economic and environmental factors, MNOs may need to take account of communication systems that are capable of providing high data rates with limited power consumption.

Among the approaches being adopted to address those environmental concerns, renewable energy sources are attracting an increasing amount of attention. As a result, it is expected that the global solar market will grow by about $14 \%$ in 2020 in terms of new installed capacity [28]. Although the net capacity additions remained flat in 2018, solar Photo Voltaic (PV) generation increased by $31 \%$, and represented the largest absolute growth of all the renewable energy technologies, being slightly ahead of wind and hydro power [29]. Fig. 1 
shows the figures for the solar PV power generation and future projections, between 2000 and 2030. [29] suggests there is an exponential pattern in the power generation obtained through PV systems, where the goal is to reach a rate of $3300 \mathrm{TWh} / \mathrm{year}$ in 2030, which corresponds to a Sustainable Development Scenario (SDS).

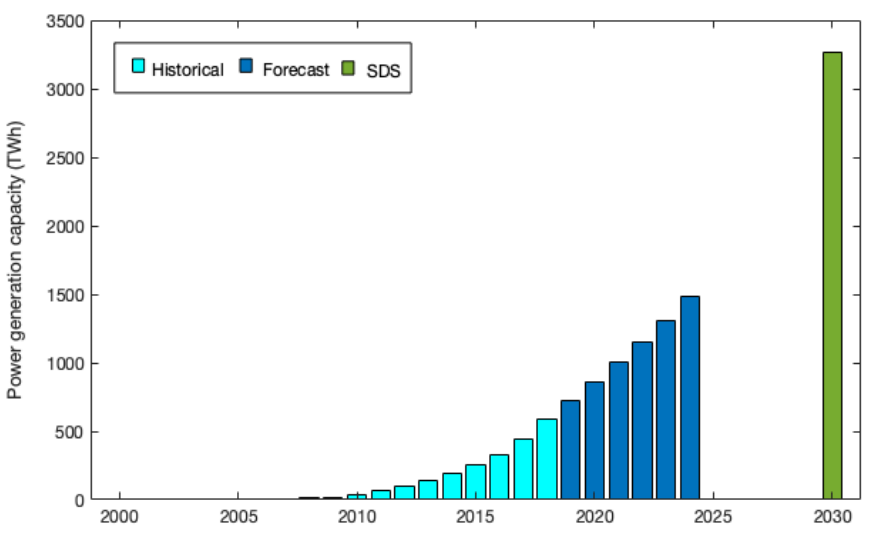

Fig. 1. Solar PV generation in the SDS 2000-2030, adapted from [29].

However, photovoltaic power generation is a project with large-scale, long-cycle, and high-risk implications [30]. Hence it should be carefully evaluated at the outset, and a considerable investment is needed to make the project profitable. Although the cost of solar PV modules has gone down by more than $90 \%$, and system prices by almost $80 \%$ in real terms during the last decade, feasible financial solutions are still needed for PV to produce the required generation capacity [31].

In view of this, we decided to adopt a closed-form analytical approach that incorporates the use of renewable energy sources in different scenarios of heterogeneous mobile networks. This includes analytical models that are designed for the technoeconomic planning of the purchasing and installation of photovoltaic equipment in HetNets. Furthermore, current work in the field seeks to expand [32] by employing a detailed and comprehensive methodology capable of evaluating not only the photovoltaic CAPEX but also of making its implementation feasible in technical, economic, operational (OPEX) and environmental terms in HetNets architectures. What differentiates this research from previous studies is that the planning and analysis of the installation and feasibility of photovoltaic systems are offered as an alternative to the conventional electricity grid since the expenses related to energy costs are crucial factors in OPEX [32]. The results obtained are validated through a sensitivity analysis where the best and worst-case scenarios are assessed from the standpoint of the mobile operators.

In light of this, the main contributions made by this paper can be summarized as follows:

- The designing of extensible analytical models aimed at dimensioning photovoltaic systems that can meet the energy demands of heterogeneous mobile network architectures. Capital and Operational expenditure are taken into account to assess the feasibility of the PV system from the standpoint of the MNO;
- Several heterogeneous mobile network architectures are evaluated, in order to make an assessment of multiple Radio Access Technologies and backhaul deployment strategies, and their impact on the overall energy consumption of the network;

- We provided a comprehensive examination of the impact of the main parameters by conducting a sensitivity analysis to evaluate their influence on the Total Cost of Ownership (TCO) and predicted cost reductions to end users;

- An estimate was made of the prevention of per-capita greenhouse gas emissions by means of a closed-form analytical model, to highlight any potential environmental benefits.

The rest of this article is structured as follows. Related works are discussed in section III Section III outlines the different architectures of heterogeneous mobile networks, the basic concepts of photovoltaic systems and their main components, as well as the contextualization and characterization of the total cost of ownership and the sensitivity analysis. Section IV] explains the analytical modeling techniques employed to assess the techno-economic feasibility of the system within the context of HetNets and mobile backhaul. The Total Cost of Ownership (TCO) is modeled in Section V, whilst the case study is examined in Section VI. The results obtained are analyzed in Section VII which includes the prevention of $\mathrm{CO}_{2}$ gas emissions, the financial situation of the end-user and how a sensitivity analysis can serve as a methodology for validation. Section VIII summarizes the main conclusions and makes suggestions for future research.

\section{RELATED WORK}

Denser cellular access networks are being extensively deployed by MNOs to meet the huge increase in the demand for mobile traffic. and this entails high energy supply costs. The use of renewable energy in the domain of telecommunications is an approach which has attracted a good deal of attention [33]-[35]. Given the technical challenges raised by the planning and installing of HetNets and their respective mobile backhaul, there has been a good deal of discussion among researchers about the question of reducing energy consumption [32], [36].

Moreover, a methodology consisting of four stages [37] has been put forward for the dimensioning of the radio and transport sector of a mobile network and making an assessment of energy consumption that is based on several possible solutions. The purpose of this assessment is to find out how energy can be used most efficiently in residential urban areas while taking account of the levels of traffic that can be expected until the year 2022. The results show that when there is low traffic, the conventional implementation of the macro BS for backhauling based on microwave technology is the best choice. However, when there are higher volumes of traffic, due to an increase in user density, the heterogeneous networks with macro BSs and small indoor base stations, they are more efficient in terms of energy and spectral efficiency. Furthermore, the energy consumption of the backhaul may represent a not negligible 
[OR not insignificant] part of the MNO's operational costs [37]. Hence, the sizing of PV systems should take account of the energy demands of the entire network, so that the related financial costs can be estimated accurately.

The authors in [38] suggest installing stand-alone solar panels together with the base stations, with the aim of solving an optimization problem and thus reducing the total cost of ownership of the network. With regard to the use of photovoltaic systems in mobile cellular networks, the authors of [39] investigated the feasibility (as well as the simulation) of a solar photovoltaic (PV)/battery hybrid power system (HPS), as a principal source of power for a particular mobile cellular BS site situated in the Soshanguve area of the city of Pretoria, South Africa. Their results showed that the solution obtained achieved a saving of about $80.87 \%$ in operating costs compared with a conventional BSs powered with a genset battery. However, the solar system model does not take account of the energy consumption of the backhaul when dimensioning the photovoltaic system and the study does not provide a complete closed-form solution to display the capital and operational expenses.

The authors in [40] designed an analytical model the location-dependent mean value and production of variable renewable energy which makes it possible, to find feasible combinations of photovoltaic (PV) panel and battery sizes, that are suitable to power a BS and make storage depletion less likely below a target threshold. By treating the RE production as a random variable, this approach addresses the question of uncertainty that is inherent in the power generated through PV systems. As well as this, the authors suggest the use of a Markovian model for evaluating the probable battery life and power consumption. Furthermore, the application of this method highlights the role of variable RE. However, once again, the energy consumption of mobile backhaul is not included when sizing the harvesting system.

In [33]], the authors investigated the adoption of cellular BSs that are supplied with renewable energy sources (RES) in an arrangement where the BS provides surplus energy to a neighboring BS, thus reducing the use of conventional energy. The study also employs a strategy for modelling the dynamic load of the BS, where there are temporal fluctuations with traffic variations. From the results obtained, different levels of low-cost energy saving can be recommended, depending on seasonal factors. Moreover, the authors ignore the sizing of capital and operational costs when assessing the way the scheme is adopted.

The authors in [41] employed a strategy for determining the minimum cost solution for a 10 -year time frame to operate an LTE (Long-Term Evolution) macro base station, using PV systems, stationary batteries, and a secondary power source (i.e. a conventional power grid system). The approach can be formalized as an optimization problem by employing Mixed Integer Programming (MIP) techniques. In addition, a heuristic algorithm has been formulated to simplify the computational complexity of the problem. Numerical results show that a hybrid solar grid (or solar-diesel) power system saved a significantly greater fraction of the total cost than a purely solar system, or the traditional power-grid system, during the investigated 10-year period. Furthermore, the study does not include estimates of prevented greenhouse gas emissions and the energy efficient mobile backhaul.

Most of the works mentioned above only take account of energy consumption occurring in the radio access network, instead of also including the demand for backhaul-energy. Nevertheless, sizing a PV generation system is a critical task, and the dimensioning methods available in the literature are mainly based on strategies involving simulation or optimization, and hence result in time-consuming or computationally complex processes. Hence to the best of our knowledge, there is a lack of studies that examine the influence of technologies used in the backhaul, for both dimensioning and assessing how PV systems can be adopted in the mobile network system.

\section{HetNets, The Photovoltaic System and TCO}

This section provides information about heterogeneous network architectures and concepts of the solar energy collection system, as well as an including description of the total acquisition costs.

\section{A. Heterogeneous Network Architectures}

This study examines the $4 \mathrm{G}$ and $5 \mathrm{G}$ architectures of the heterogeneous networks outlined in [37] as a means of sizing and assessing the use of photovoltaic systems in the context of mobile networks. In this work, two types of BS are included - macro and small cell, in a way that ensures that the outdoor users are catered by macrocells, while the indoor users can be catered by both types of BS. Two types of strategies are examined here for the provisioning of small cells.

The first employs the concept of a Distributed indoor Radio Architecture (DRA) deployment and is an installation strategy that is generally carried out by the operator of a mobile network. The second kind of strategy is based on the uncoordinated use of small cells which are generally installed by the end-users of the mobile networks. The DRA comprises three key features: (i) The indoor antenna which is fitted with a radio signal amplifier, (ii) a remote radio unit, responsible for conducting analog signal processing and signaling with antennas and (iii) the digital unit which carries out the digital baseband processing which includes interference management and cell interference coordination. A wide range of digital units can be aggregated in a single data center, known as the Digital Unit Hotel (DU Hotel). Also, [37] notes the use of two DRA-based architectures. These are divided between architectures and technologies used in the transport network layer. In the first of these architectures, referred to as Macro+DRA-BF (DRA Building Fronthaul Architecture), each building has a set of antennas, a Remote Radio Unit (RRU) and an Optical Network Unit (ONU), which interlink the buildings to a central office, and by the use of a passive optical network, to the Optical Line Terminal (OLT) and in this way, to the DU Hotel, as illustrated in Figure 2(a). In the second DRA architecture, referred to as Macro+DRA-CF (DRA Curb Fronthaul Architecture), the RRU is hosted in street cabins and can serve more than one building. The RRU 

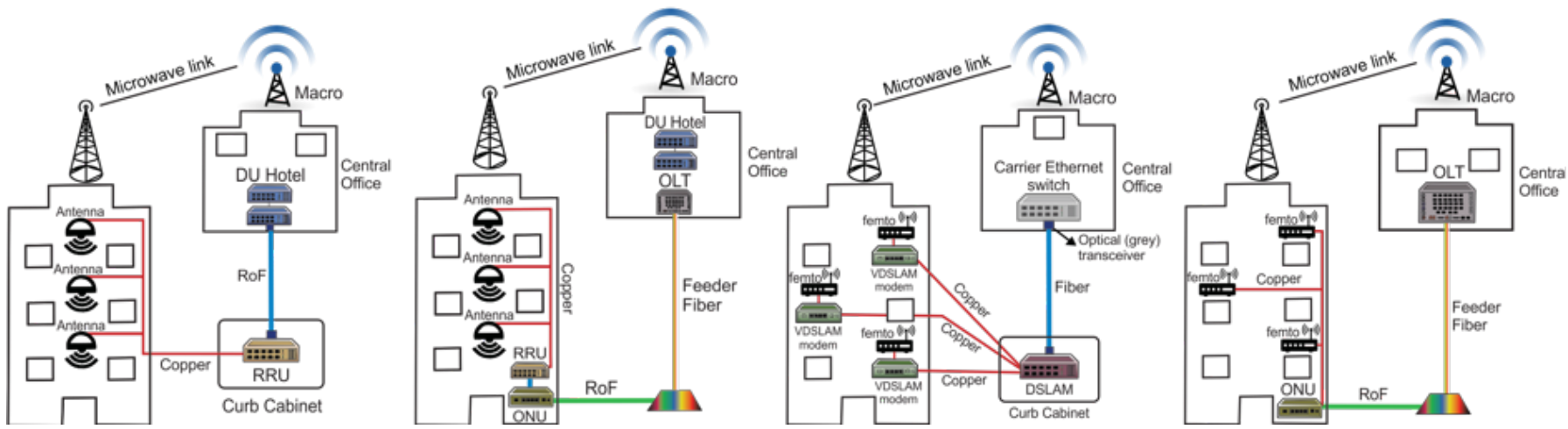

Fig. 2. Architectures outlined in [37]: (a) DRA curb fronthaul architecture (DRA-CF); (b) DRA building fronthaul architecture (DRA-BF); (c) Femto-Based curb backhaul architecture (Femto-CB); (d) Femto-Based building backhaul architecture (Femto-BB).

is interlinked to the DU Hotel, using optic fiber, and uses the Radio-Over-Fiber (RoF) protocols, as shown in Figure 2(b).

Concerning the installation based on the use of small cells, these are generally residential buildings that are installed at random by the end-users and thus do not follow any installation strategy adopted by the MNO. Moreover, by considering the DRA-based architectures, the authors of [37] examine the use of two architectures based on the use of femtocells. In the first of these architectures, referred to as Macro+FemtoCB (Femto-Based Backhaul Architecture), each femtocell is connected to a Very-high-bit-rate Digital Subscriber Line (VDSL) modem, and then to a Digital Subscriber Line Access Multiplexer (DSLAM) using copper. Later, the curb cabinet is connected to the central office, through the use of fiber-optic and a gigabit ethernet switch for carrier solutions, as shown in Figure 2(c). Finally, in the Macro+Femto-BB (FemtoBased Building Backhaul) architecture, all the small cells of a building are connected by copper to an ONU, which in turn is connected to the OLT in the Central Office through a fiber optic distribution (PON), with a time-domain multiplexing approach and TDWDM wavelength, as shown in Figure 2(d).

\section{B. Contextualization and Characterization of the Photovoltaic System}

Every day the sun emits a large amount of energy which reaches the planet surface, free of charge and clean. This solar energy can be exploited directly in the form of light and heat since it can be converted into electric power by photovoltaic cells. The performance of the photovoltaic cells is influenced by a wide range of factors, such as temperature and manufacturing material, but mainly by incident solar radiation which is controlled by the intensity with the solar energy reaches the Earth $\left(\mathrm{kWh} / \mathrm{m}^{2}\right.$.day) and is subject to regional and seasonal variations.

The solar energy collection system (also called the photovoltaic system) can be categorized as off-grid and is connected to the network [42]. In the off-grid systems, the entire generation of energy is stored in energy storage structural composites (stationary batteries), which allow energy to be used at any time of the day. In general, batteries are not used for the systems connected to the network, since at nighttime the electric power that is needed, has to be obtained through the conventional energy network, as shown by Figure 3.

For this study, the photovoltaic system connected to the network is adopted because it incurs lower maintenance costs than the off-grid system, as well as being able to guarantee uninterrupted available electric power. Moreover, there are no extra costs from the need to acquire stationary batteries. The collector structure consists of the following: (i) a photovoltaic panel which is made up of organic solar cells arranged in a pattern, the purpose of which is to produce electric power, (ii) a solar inverter connected to the network, responsible for the conversion of direct current to alternating current and (iii) a two-way net meter, a device responsible for measuring the energy generated by the photovoltaic system, as well as the amount of energy that can, if necessary, be consumed by the electric power contractors [42].

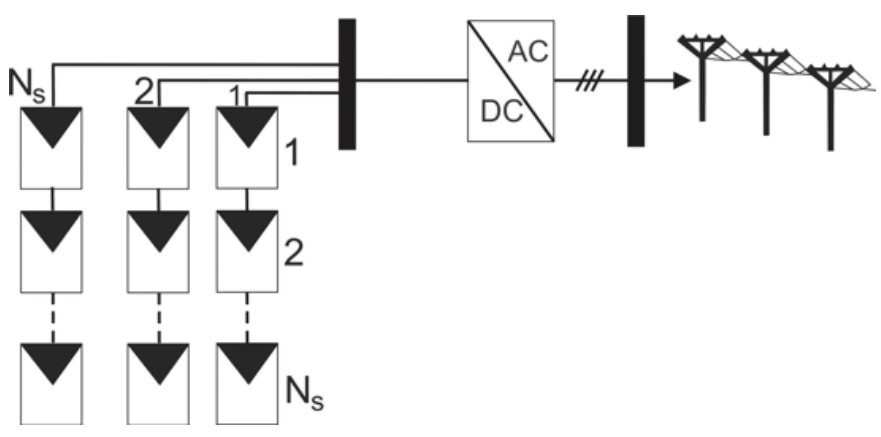

Fig. 3. Solar system harvesting scheme connected to the network [43].

\section{Calculation of Total Acquisition Costs}

By considering energy harvesting from the solar power collectors, an assessment must be made of the Total Cost of Ownership (TCO) which calculates the financial costs incurred by the acquisition, installation, operation, and maintenance of the collector system. When these parameters are estimated accurately, they can prove to be profitable for the mobile operator and potentially for the end-users of the network as well.

The TCO consists of capital expenditure (CAPEX), as well as operational expenses (OPEX). CAPEX is obtained by 
adding together the costs of acquisition and the installation of equipment, such as modules, inverters and mounting structure (for the installation of solar panels in flat or sloping roofs). As well as this, the costs related to the installation of the photovoltaic equipment, are calculated on a percentage basis and represent the financial sum needed to purchase this equipment.

The OPEX refers to the expenses incurred during the operation and maintenance (O\&M) of the system, which is generally shown annually. It consists of three basic costs: (i) operation and maintenance of the photovoltaic equipment, (ii) renting physical space for installing the panels, (iii) the electric power coming from the energy provider; and iv) the expenses linked to the cost of installing the two-way meters. Also, it is necessary to take into account the minimum monthly consumption of electricity by the bidirectional liquid meter $(\mathrm{kWh})$, which generates an additional financial value (based on the electricity tariff) that must be added to the OPEX calculation.

The calculation of the photovoltaic TCO related to the photovoltaic system is not sufficient to explain its financial attraction, since its installation depends on several factors, such as the following: costs related to panel and inverters, assembly structure and rent. When analyzing these financial feasibility issues that involve decision making and studying a sensitivity analysis, it can be useful to determine the main cost factors that must be carefully examined when installing a photovoltaic structure.

\section{Sizing the Photovoltaic System}

The section sets out the analytical models employed to estimate $(i)$ the total energy consumption of the heterogeneous architectures of mobile networks outlined in [37], (ii) the total amount of energy generated by the collector system and (iii) the emissions of $\mathrm{CO}_{2}$ that were prevented during the period being analyzed.

\section{A. Energy Demands of Backhaul}

The energy consumption of each HetNet architectures presented in Section III is denoted by $E_{\text {backhaul. }}$. E backhaul is the result of the sum between the mandatory minimum consumption of the local electricity dealer $\left(E_{n e t}\right)$ and the electrical energy supply that must be generated by the solar energy collection system to provide the needs of the backhaul mobile network $\left(E_{g e n}^{\min }\right)$. Hence, $E_{\text {backhaul }}$ is computed as:

$$
E_{\text {backhaul }}=E_{\text {gen }}^{\text {min }}+E_{\text {net }},
$$

where $E_{\text {gen }}^{\text {min }}$ and $E_{n e t}$ are expressed in $\mathrm{kWh}$. The term $E_{\text {net }}$ can be computed as:

$$
E_{n e t}=N_{m e t} \cdot E_{m e t}^{\text {min }},
$$

where $N_{\text {met }}$ and $E_{\text {met }}^{\text {min }}$ represents the number of two-way net meters and the minimum consumption of the network by the meter (kWh), respectively. The number of meters is assumed to be equal to the number of inverters used in the mobile network architecture $\left(N_{i n v}=N_{m e t}\right)$, for convenience reasons.

\section{B. Generation of Photovoltaic Solar Energy}

In this stage, the total generation of electrical power from the photovoltaic collector system $\left(E_{g e n}\right)$ is modeled to meet the energy requirements of the HetNet architecture. The term $E_{\text {gen }}$ is computed as:

$$
E_{g e n}=N_{i n v} \cdot E_{i n v},
$$

where $N_{\text {inv }}$ represents the number of inverters needed to supply power to a given architecture and can be calculated by the term $N_{i n v}=\left\lceil\frac{E_{g e n}^{m i n}}{E_{i n v}}\right]$. Thus, it can be inferred that $E_{g e n} \geq E_{g e n}^{\text {min }}$, since the value of $N_{i n v}$ is rounded to the above to allow the volume of energy that is effectively generated to be greater than the minimum necessary. Additionally, the volume of energy generated daily by an inverter $\left(E_{i n v}\right)$, given in $\mathrm{kWh}$, is computed as:

$$
E_{i n v}=\xi_{i n v} \cdot N_{i n v}^{p} \cdot E_{p}
$$

where $\xi_{i n v}, N_{i n v}^{p}$ and $E_{p}$ represent respectively the inverter efficiency, the number of solar panels that can be installed per inverter and the amount energy generated per solar panel. The term $N_{i n v}^{p}$ is given by:

$$
N_{i n v}^{p}=\left\lceil\frac{P_{i n v} \cdot t_{s}}{E_{p}}\right\rceil,
$$

where $P_{i n v}$ and $t_{s}$ represent the nominal potential that gives entrance to the inverter $(\mathrm{kW})$ and the average exposure time of the photovoltaic panels to the sun (hours) per day, respectively. The term $E_{p}(\mathrm{kWh})$ is computed as:

$$
E_{p}=A_{p} \cdot \xi_{p} \cdot \gamma_{s} \cdot \varphi_{p},
$$

where $A_{p}, \xi_{p}$ and $\gamma_{s}$ represent the area of a solar panel $\left(\mathrm{m}^{2}\right)$, the panel efficiency and the intensity of the daily solar radiation incident $\left(k W h / m^{2} . d a y\right)$, respectively. The $\varphi_{p}$ parameter represents the rate of performance loss of the panel over the years which varies on a descending scale.

\section{Prevention of Greenhouse Gas Emissions}

The total amount of $\mathrm{CO}_{2}\left(\kappa_{\mathrm{CO}_{2}}\right)$ that is no longer emitted into the atmosphere $\left(\mathrm{kgCO}_{2}\right)$ as a result of using the photovoltaic collector system is represented by the following expression:

$$
\kappa_{\mathrm{CO}_{2}}=E_{\text {gen }} \cdot \varepsilon_{\mathrm{CO}_{2}}
$$

where $\varepsilon_{\mathrm{CO}_{2}}$ represents the emission factor of $\mathrm{CO}_{2}$ per $\mathrm{kWh}$ of energy which ceased to be consumed by the electrical power network $(\mathrm{kgCO} / \mathrm{kWh})$, as calculated in [44].

Besides, the equivalent carbon dioxide metric $\left(\mathrm{CO}_{2 e q}\right)$ for an estimate of how much global warming a given type and amount of Greenhouse Gas (GHG) may cause, using the functionally equivalent amount or concentration of carbon dioxide $\left(\mathrm{CO}_{2}\right)$ as the reference. Hence, by considering that the global warming potential of $\mathrm{CO}_{2}$ is defined as 1 , we can assume that $\kappa_{\mathrm{CO}_{2}}=\kappa_{\mathrm{CO}_{2 e q}}$ [45]. To asses the impact of avoided emissions, we consider an equation to represent 
these avoided emissions in projections of GHG emissions from deforestation in Amazon Forest using the term $A_{D}$. For this representation, the average biomass volume from several Brazilian biomes is used to estimate the amount of carbon per territorial unit (hectare), as presented as follows [46]:

In addition, the carbon dioxide equivalent metric $\left(\mathrm{CO}_{2 e q}\right)$ is used to generate an estimate of how much global warming a given type and amount of Greenhouse Gases (GHG) can cause. For this estimate, the functionally equivalent amount or concentration of carbon dioxide $\left(\mathrm{CO}_{2}\right)$ is used as a reference. Therefore, considering that the global warming potential of $\mathrm{CO}_{2}$ is defined as 1 , we can assume that $\kappa_{\mathrm{CO}_{2}}=\kappa_{\mathrm{CO}_{2 e q}}$ [26]. To assess the impact of avoided emissions, we consider an equation to represent these avoided emissions in projections of GHG emissions from deforestation in the Amazon Forest using the term $A_{D}$ [46]. For this representation, the average volume of biomass from several Brazilian biomes is used to estimate the amount of carbon per territorial unit (hectare), as shown:

$$
A_{D}=\frac{\kappa_{C O_{2 e q}}}{\mu_{h a} \cdot \phi_{C O_{2}}}
$$

where $\mu_{h a}$ represents the average value of carbon emissions per forest territorial unit $(\mathrm{kgC} / \mathrm{ha})$ and $\phi_{\mathrm{CO}_{2}}$ represents the equivalence factor between Carbon and Carbon Dioxide.

\section{Modelling of the Total ACQuisition Costs}

This section examines the analytical models employed for the sizing of the total scale of acquisition, operations, and maintenance of the collector system as a result of the energy demands of HetNets shown in [37]. Thus, the total value of the acquisition of the photovoltaic infrastructure $(T C O)$ can be expressed as:

$$
T C O=C A P E X+O P E X,
$$

where $C A P E X$ and $O P E X$ represent the cost of acquisition and installation of equipment, as well as the operational and maintenance costs respectively.

\section{A. Capital Costs}

The Capital Expenditures $(C A P E X)$ can be described as:

$$
C A P E X=\left(1+\tau_{\text {install }}\right) \cdot C_{\text {equip }},
$$

where $\tau_{\text {install }}$ and $C_{\text {equip }}$ represent the charge for installation and the initial cost of acquiring photovoltaic equipment respectively. The initial cost of acquiring equipment (panels, inverters and installation kits) is calculated as:

$$
C_{\text {equip }}=\sigma \cdot\left[N_{p} \cdot\left(C_{p}^{u n i t}+C_{k i t}^{u n i t}\right)+N_{i n v} \cdot C_{i n v}^{u n i t}\right],
$$

where $N_{p}$ represents the number of interlocking panels in the inverters, which is given by $N_{I n v} \cdot N_{i n v}^{p}$, whereas $C_{p}^{u n i t}$, $C_{\text {kit }}^{\text {unit }}$ and $C_{i n v}^{u n i t}$, represent, the unitary cost of the photovoltaic panels the installation kit and the inverter respectively. We assume that photovoltaic inverters are already equipped with installation kits included, and consequently, modeling of installation kits for inverters as a system variable was not carried out. The parameter $\sigma$ represent an annual rate of depreciation of the cost of acquiring the photovoltaic equipment and simulate a possible technological evolution and a means of making this equipment popular and hence reducing manufacturing and purchasing costs.

\section{B. Operational and Maintenance Costs}

The Operational Expenditures $(O P E X)$ are defined as:

$$
O P E X=C_{O \& M}+C_{m e t}^{\text {total }}+N_{p} \cdot A_{p} \cdot C_{m^{2}}^{r e n t},
$$

where $C_{O \& M}$ and $C_{m e t}^{\text {total }}$ represent, the operational and maintenance costs of the solar collector system and total costs associated with two-way net meters. The collector system O\&M cost may involve cleaning the photovoltaic panels, preventive or corrective measures taken to maintain the structures that support the panels and inverters, as well as skilled labor and related expenses. As well as this, $N_{p}, A_{p}$ and $C_{m^{2}}^{r e n t}$ represent respectively, the total number of panels used in the architecture, the area where there is only a single panel, and the annual rental charge by $m^{2}$ of the roofs of the buildings where the panels have been installed. The term $C_{\text {met }}^{\text {total }}$ is obtained as:

$$
C_{m e t}^{\text {total }}=N_{\text {met }} \cdot\left(C_{m e t}+E_{m e t} \cdot C_{\text {purch }}^{k W h}\right),
$$

where $N_{m e t}, C_{m e t}, E_{m e t}$ and $C_{\text {purch }}^{k W h}$ represent respectively, the number of two-way net meters, the minimum energy consumption of the conventional network allowed by the meter, the financial cost of installing the meter individually and the price charged for the $\mathrm{kWh}$ of the dealership. The cost of O\&M of the photovoltaic equipment is calculated as:

$$
C_{O \& M}=\tau_{O \& M}\left[C_{p, k i t}^{\text {manut }}+\left(N_{i n v} \cdot C_{i n v}^{u n i t} \cdot N_{m i}\right)\right]
$$

where $\tau_{O \& M}$ represents the annual charge of O\&M incurred by the equipment, $N_{i n v}, C_{i n v}^{u n i t}$ and $N_{m i}$ represent the number of inverters used in a given architecture, the cost of purchasing the inverters and the number of maintenance sessions for these inverters. The total cost of maintenance of the panels and kits $\left(C_{p, k i t}^{\text {manut }}\right)$ can be expressed as:

$$
C_{p, k i t}^{\text {manut }}=N_{p} \cdot\left(C_{p}^{u n i t} \cdot N_{m p}+C_{k i t}^{u n i t} \cdot N_{m k}\right),
$$

where $C_{p}^{\text {unit }}, N_{m p}, C_{k i t}^{u n i t}$ and $N_{m k}$ represent the unitary cost of acquiring the solar panel, the number of maintenance sessions for each individual panel, the cost of purchasing the installation kit with regard to a single photovoltaic module, and the number of maintenance sessions for the installation kit, respectively. The number of maintenance sessions required for the kits and inverters is represented in Figure 4

According to Figure 4, the variable $t$ represents the period of analysis (in years), during which there will be an assessment of the feasibility of using photovoltaic equipment. In the context of this study, there is a need to define a period of analysis, since some of the equipment, such as the photovoltaic panel, can still have a useful life beyond the period of 30 years. As well as 


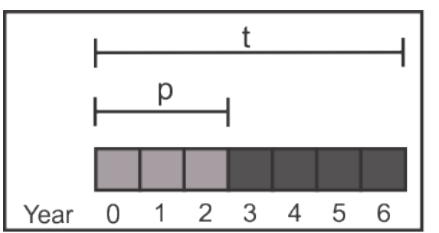

(a)

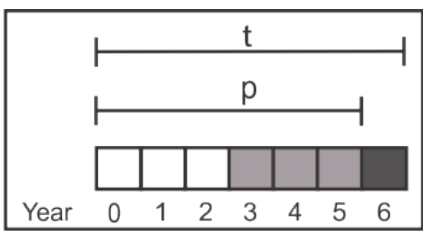

(b)

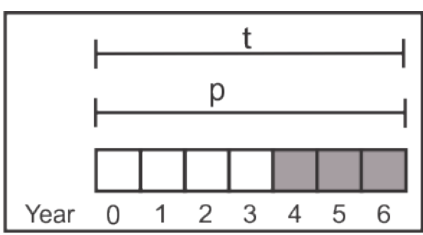

(c)

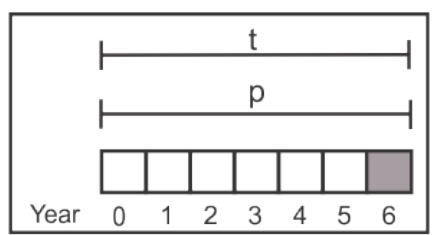

(d)

Equipament warranty

Maintenance numbers

$t$ Analisys time

$p \quad$ Period between the first year of $t$ and the last year of the warranty

Fig. 4. Calculation of the number of maintenance sessions carried out for the photovoltaic equipment.

this, the prediction of energy consumption is envisaged for a shorter period and beyond this projection and has a pattern of growth for each year. Thus, in the analytical modeling conducted in this study, it was decided only to analyze the installation of the photovoltaic system within the projected period of energy consumption.

As shown in Figure 4, $p$ represents the period between the beginning of period $t$ and the end of the guarantee of the equipment under consideration (installation kits or inverters), also represented in terms of years. In this way, the number of maintenance sessions carried out in the inverters and installation kits is equivalent to the period in years when the equipment was covered by guarantee policies within the analytical interval of the photovoltaic structure $t$, when considering one maintenance unit per piece of equipment for each year.

For instance, suppose there is a period of $t=7$ years, and that a given photovoltaic piece of equipment has a guarantee of $p=3$ years. Based on this assumption, according to Figure 4 (a), if this equipment was acquired in Year 0 , it will be covered by the guarantee until the end of Year 2 (making a total of 3 years). Thus, this equipment should receive at least 4 maintenance sessions, with one being carried out each year, within the observation period $t$. If the equipment was acquired in Year 4, as is the case in Figure 4(c), it will not be subject to maintenance sessions within the period of analysis $t$, since the end of this warranty coincides with the end of this period $(t)$. The other examples in Figure $4(\mathrm{~b})$ and $4(\mathrm{~d})$ follow the same rationale. Thus, Eq. (16) generalizes the total number of maintenance sessions carried out in the photovoltaic equipment, as:

$$
f\left(m_{x}\right)=\left\{\begin{array}{l}
t-p_{x}, \text { if } t>p_{x} \\
0, \text { otherwise }\left(t<=p_{x}\right)
\end{array}\right.
$$

Thus, there is $N_{m k}=N_{m i}=f\left(m_{x}\right)$, in which $x \in$ $\{k i t s$, inverters $\}$, whereas the number of maintenance sessions carried out in the photovoltaic panels is represented by $N_{m p}=t$, since in this study, annual preventive maintenance for the photovoltaic panels is also taken into account. In this study, there is a need to define a period of analysis since some of the equipment, such as the panel, has a useful life that may exceed 25 years when the forecast for energy consumption is planned to cover 21 years. As a result, in analytical modeling, it was decided only to analyze the collector system within the period of energy consumption projected by the heterogeneous networks.

\section{Monetary Economy of the Users}

The end-users financial situation is given as:

$$
A S_{\text {user }}=\frac{\left(E_{e} \cdot C_{\text {sale }}^{k W h}+E_{\text {backhaul }} \cdot C_{\text {purch }}^{k W h}\right)-T C O}{\rho \cdot A}
$$

where $C_{\text {sale }}^{k W h}$ and $C_{\text {purc }}^{k W h}$ represent the sale and acquisition price of the $\mathrm{kWh}$ respectively, that are quoted by the dealer. At the same time, $\rho$ is the equivalent of the population density of the users (users $/ \mathrm{km}^{2}$ ) and $A$ represents the residential area $\left(\mathrm{km}^{2}\right)$, while the term $E_{e}$ represents the amount of excess electricity $\left(E_{e}=E_{g e n}-E_{g e n}^{\min }\right)$.

\section{Tools for the Analysis of Sensitivity}

The analysis of sensitivity makes it possible to determine the main aspects of costs that are apparent in the variability of the photovoltaic TCO. Since the cost parameters are separate from each other, they can be treated individually as constant values and when a percentage variation represented by the [$30 \%$ to $30 \%$ ] interval is applied, new indicators emerge which can be integrated into the analysis of economic viability.

\section{The CASE Study}

As described in [37], this study involved including a geographical area of $100 \mathrm{~km}^{2}$, with an average population density of 3,000 users per $\mathrm{km}^{2}$. The number of buildings in the area under investigation is 10,000 , each building having 5 floors making a total of 15 apartments per building. The users were spread out in the residential buildings in a uniform way. Considering [37] this penetration rate is $60 \%$ indoor and $40 \%$ outdoor, however, following the trends predicted for the years ahead, the model used in the current work was parametrized with a penetration rate of $80 \%$ indoor and $20 \%$ outdoor [47]. This case study reproduces the mathematical results and models of [37], as a means of obtaining the pattern of energy consumption of the HetNets architectures.

Concerning the parameters of the photovoltaic system being put forward, Table I shows the parameters used in the harvesting system, which comprises information about the inverter, photovoltaic panel, panel structure, solar radiation, and TCO. For the inverter, an appropriate model is employed for selfconsumption in residential or commercial systems of a low tension with a rate of efficiency of $98.8 \%$, a warranty of 10 years and a rated power input of $61 \mathrm{~kW}$, which is compatible with the power of solar panels [48]. 
Table I also provides information about the photovoltaic panel and the mounting structure. The module is formed of polycrystalline silicon and has an area of $1.918828 \mathrm{~m}^{2}$, an efficiency rate of $16.68 \%, 320 \mathrm{~W}$ of rated output power and useful life of about 25 years. There is a loss of power experienced annually which is equivalent to $0.5 \%$ [49]. The panel is assembled by a mounting structure in a horizontal way, or other words, without a sloping angle. The aim of this to take account of scenarios that are less favorable for capturing solar radiation and thus making it more important to assess the viability of the TCO. Also, it has a 12-year guarantee and the material used in manufacturing provides a resistant support structure, both to corrosion and climatic and atmospheric conditions [50].

The required conditions for solar irradiation and average sunshine duration, depend entirely on the climate of the region where it is intended to install the system for capturing energy. The first ranges from 2.0 to $7.5 \mathrm{kWh} / \mathrm{m}^{2}$.day and the second from 3.0 to 10.0 hours, respectively, according to [51]. The factor of $\mathrm{CO}_{2}$ gas emissions used to estimate the prevention of the release of $\mathrm{CO}_{2}$ into the atmosphere by kilowatt $(\mathrm{kg})$ per hour, on the part of the supplier, is in the interval of 0.1 to $1.0 \mathrm{~kg} / \mathrm{kWh}$. Countries such as the United States and China have emission factors ranging between 0.6 and $0.9 \mathrm{~kg} / \mathrm{kWh}$ [45], [52].

The values related to the unit cost of the current inverter, photovoltaic panel, mounting structure of the panels and installation of the two-way net meter are $\mathrm{R} \$ 21,619.48$ [48], $\mathrm{R} \$ 635.00$ [49], $\mathrm{R} \$ 199.75$ per panel [50] and $\mathrm{R} \$ 300.00$ for the net meter, respectively. The depreciation of the purchase price of the equipment corresponds to $5 \%$ per year. This means that it is reduced to a maximum of $60 \%$ from the original price of the products. Maintenance and operating costs are $1 \%$ per year, based on initial investment costs. Other input data for the calculation of the $T C O$ are based on the installation costs of the photovoltaic equipment which include manpower and the engineering project; these are equivalent to $20 \%$ of the initial value of the equipment [53].

Table I also shows the purchase cost per $\mathrm{kWh}$, which represents the average energy tariffs of the 27 Brazilian capital cities in 2018. This only includes a type of tax and the sale cost per $\mathrm{kWh}$, which represents the tariff-related to transmission, distribution, charges, and taxes [57]. Moreover, the customer (MNO) must pay for the minimum consumption per net meter. This minimum consumption is equivalent to $100 \mathrm{kWh}$ per month since Brazilian legislation stipulates that the costing of energy availability should be borne by the electrical power suppliers [58].

Finally, this case study involves an analysis to calculate the estimated reduction in gas emissions $\mathrm{CO}_{2}$, as well as financial savings for end-users. The first is carried out as a result of the volume of electrical energy that is no longer consumed from the traditional matrix of electrical energy. This effect provides evidence of the possible benefits derived from the reduction of air pollution caused by the use of photovoltaic solar energy collection.

The second is linked to the energy-saving that the operators can achieve by adopting the collector system. This can be
TABLE I

SYSTEM PARAMETERS

\begin{tabular}{|c|c|c|}
\hline General Parameters & Values & Ref. \\
\hline Geographical area $(A)$ & $100.0 \mathrm{~km}^{2}$ & $\mid 37$ \\
\hline User density $(\rho)$ & 3.000 users $/ \mathrm{km}^{2}$ & \\
\hline Indoor penetration rate & 0.8 & 47 \\
\hline Outdoor penetration rate & 0.2 & 47 \\
\hline Inverter Parameters & Values & Ref. \\
\hline Warranty period & 10 years & \\
\hline Inverter efficiency $\left(\xi_{\text {inv }}\right)$ & $98.8 \%$ & {$[48$} \\
\hline Inverter input power $\left(P_{\text {inv }}^{\text {input }}\right)$ & $61 \mathrm{~kW}$ & \\
\hline Photovoltaic Parameters & Values & Ref. \\
\hline Panel technology & Polycrystaline silicon & \\
\hline Panel warranty period & 10 years & \\
\hline Panel area $\left(A_{p}\right)$ & $1.918828 \mathrm{~m}^{2}$ & {$[49$} \\
\hline Panel efficiency $\left(\xi_{p}\right)$ & $16.68 \%$ & \\
\hline Annual power loss $\left(\tau_{\text {loss }}\right)$ & $0.5 \%$ per year & \\
\hline Fixation structure warranty & 12 years & 50 \\
\hline Solarimetric Parameters & Values & Ref. \\
\hline Solar Radiation $\left(\gamma_{s}\right)$ & $2.0-7.5 \mathrm{kWh} / \mathrm{m}^{2}$. day & {$[51]$} \\
\hline Average duration sunlight $\left(t_{s}\right)$ & $3.0-10.0$ hours/day & \\
\hline TCO Parameters & Values & Ref. \\
\hline Rental cost $\left(C_{m^{2}}^{r e n t}\right)$ & $\mathrm{R} \$ 183.96$ year $/ \mathrm{m}^{2}$ & 54 \\
\hline Inverter Unit Price $\left(C_{i n v}^{u n i t}\right)$ & $\mathrm{R} \$ 17,293.50$ & 48 \\
\hline Panel Unit Price $\left(C_{p}^{u n i t}\right)$ & $\mathrm{R} \$ 721.71$ & [49] \\
\hline Netmeter Unit Price $\left(C_{m e t}\right)$ & $\mathrm{R} \$ 300.00$ & $\mid 55$ \\
\hline Install Kit Unit Price $\left(C_{k i t}^{u n i t}\right)$ & $\mathrm{R} \$ 199.75 /$ panel & $|50|$ \\
\hline Annual maint. charge $\left(\tau_{O \& M}\right)$ & $1 \%$ per year & 55 \\
\hline Depreciation Rate $(\sigma)$ & $5 \%$ per year & [56 \\
\hline Installation charge $\left(\tau_{\text {install }}\right)$ & $20 \%$ & |53 \\
\hline $\mathrm{kWh}$ purchase price $\left(C_{\text {purch }}^{k W h}\right)$ & $\mathrm{R} \$ 0.67$ & 57 \\
\hline kWh selling price $\left(C_{\text {sale }}^{k W h}\right)$ & $\mathrm{R} \$ 0.54$ & |57| \\
\hline Min. consumption $\left(E_{m e t}^{m i n}\right)$ & $1,200.00 \mathrm{kWh}$ per year & $\mid 58$ \\
\hline Environmental Parameters & Values & Ref. \\
\hline $\mathrm{CO}_{2}$ emission factor $\left(\varepsilon_{\mathrm{CO}_{2}}\right)$ & $0.1-1.0 \mathrm{kgCO} / \mathrm{kWh}$ & {$[45],[52]$} \\
\hline Avg. carbon emission $\left(\mu_{h a}\right)$ & 132.3 ton $C / h a$ & {$[46$} \\
\hline Equivalence factor $\left(\phi_{\mathrm{CO}_{2}}\right)$ & $44 / 12$ & [46] \\
\hline
\end{tabular}

reflected in a positive way (either directly or indirectly) for the accounts of the end-users using, for example, promotional benefits and financial investment in improved technology. The second is associated with the energy-saving process that the operators can achieve by adopting the collector system. This can be reflected in positive terms (either directly or indirectly) for the accounts of the end-users using, for example, promotional benefits and financial investment in improved technology.

\section{NUMERICAL RESULTS}

In this section, we look at the results of $T C O$ and the prevention of $\mathrm{CO}_{2}$ gas emissions through heterogeneous mobile networks presented in Figure 2 .

\section{A. Techno-Economic and Environmental Evaluation}

Before it can be regarded as profit within the domain of HetNets, the photovoltaic collector system must have a Total 
Acquisition Cost that is lower than the values presented in Table II. If the opposite is the case, the cost of energy coming from the supplier will involve a higher return of profit. Table II traces the accumulated consumption of electricity over 21 years, differently from [37] which considers 15 years, converted into Brazilian Real ( $\mathrm{R} \$)$, as a means of showing the total reference value for the assessment of what is acquired from the solar collector system.

TABLE II

REFERENCE VALUES FOR ENERGY CONSUMPTION COSTS WITHOUT THE USE OF PHOTOVOLTAIC SYSTEM [37]

\begin{tabular}{|c||c|}
\hline HetNet Architecture & Millions of R\$ \\
\hline Macro+DRA-CF & 484.74 \\
Macro+DRA-BF & 525.97 \\
Macro+Femto-CB & 591.72 \\
Macro+Femto-BB & 452.83 \\
\hline
\end{tabular}

Moreover, Figure 5 shows the TCO of the collector structure as a result of the intensity of solar radiation. Taking account of a static density of 3.000 users $/ \mathrm{km}^{2}$, whereas the average solar duration $\left(t_{s}\right)$ is 6.0 hours. In addition to the data displayed in Table II, Figure 5 provides evidence of the financial benefits of installing a photovoltaic collection system in regions of the world where incident solar radiation is higher than $5.0 \mathrm{kWh} / \mathrm{m}^{2}$.day. This yield can be guaranteed when the $T C O$ has rates that range between approximately $\mathrm{R} \$ 480$ to 600 million, whereas the cost of electricity ranges from $\mathrm{R} \$ 484.74$ to 591.72 million, according to Table II. This is evidence that the $T C O$ is profitable concerning the cost of electricity coming from the supplier, as a result of the savings made by the investor from the photovoltaic undertaking, which is higher than the total costs incurred by the project.

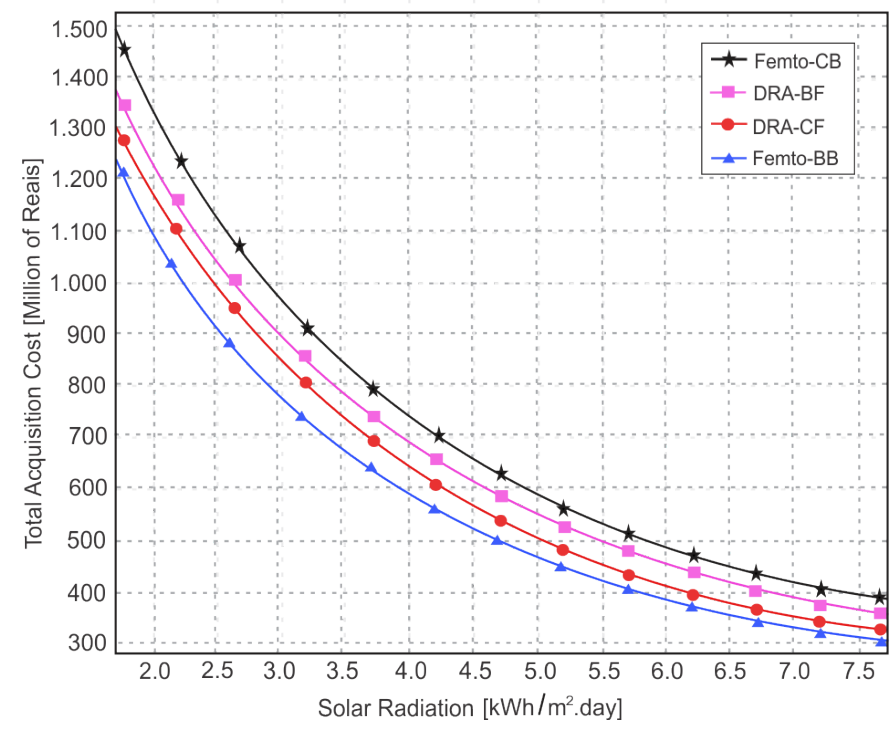

Fig. 5. Photovoltaic TCO in accordance with solar radiation $\left(\mathrm{kWh} / \mathrm{m}^{2}\right.$.day).

In addition, Figure 6 shows the expected savings for the users by showing the electricity expenses that cease to be charged as a result of the installation of the photovoltaic collector system. It should be noted here that all the architectures show a negative value for the user when the intensity of the solar radiation is below $5.0 \mathrm{kWh} / \mathrm{m}^{2}$.day, which means that in this case, the system for supplying energy, is more expensive than the traditional model. However, in environmental terms, the photovoltaic system continues to be beneficial because it emits less $\mathrm{CO}_{2}$ than the traditional systems, which rely on fossil fuels, as presented by Figure 7

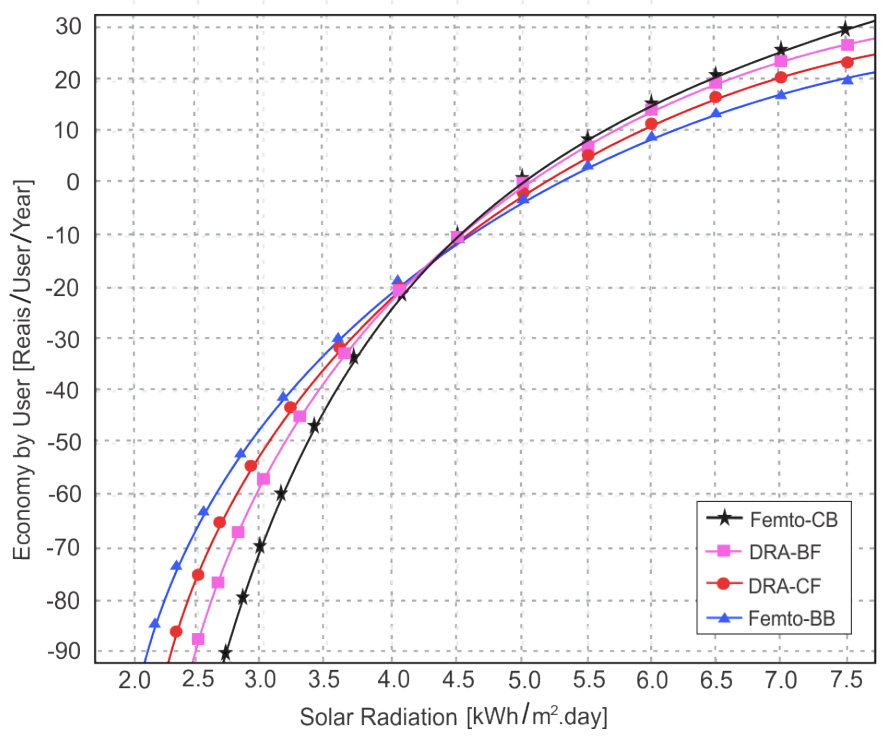

Fig. 6. Economic savings for the users as a result of solar radiation $\left(k W h / m^{2} . d a y\right)$.

On the basis of a technological and economic analysis, the results showed a different conclusion could be reached [37]. This means that while systems of sustainable energy are being installed, technical decisions about what kind of network architecture is required, must be defined very carefully. It cannot be chosen simply on the basis of how its equipment may affect the network performance, but must also be aware of its power consumption. Hence, when the solar irradiation rates are higher than $5.0 \mathrm{kWh} / \mathrm{m}^{2}$.day, the use of the Femto$\mathrm{CB}$ architecture (based on a $4 \mathrm{G}$ framework) begins to be more viable in financial terms to the detriment of other alternatives This is because its energy consumption is greater than the others, which makes the photovoltaic system profitable in a shorter period of time. With regard to the DRA-BF and DRA$\mathrm{CF}$ architectures, both have intermediate savings for the $4 \mathrm{G}$ architectures.

These architectures also show significant variations with regard to the source of the energy supply. In this case, from a baseline of $5.0 \mathrm{kWh} / \mathrm{m}^{2}$.day, , the DRA-BF architecture (based on the $5 \mathrm{G}$ framework) appears to be more economically feasible than the other alternatives. At the same time, the DRA$\mathrm{CF}$ architecture (based on the 5G framework) appears to be less feasible.. Hence, from the perspective of the users, the results suggest that in the case of regions where the incident solar radiation is below $5.0 \mathrm{kWh} / \mathrm{m}^{2}$.day, it does not matter which heterogeneous architecture is employed to install the photovoltaic system, because the operators will not be able to fulfill their expectations with regard to profits in any of the scenarios that have been outlined. 
However, making an installation economically viable depends not only on solar radiation but on other factors that must be carefully examined. These include making an initial outlay, the revenue obtained while the network is in operation, time variations, and the reliability of the photovoltaic system, among other factors. On the other hand, in the case of areas where the radiation is above $5.0 \mathrm{kWh} / \mathrm{m}^{2}$.day, any architecture can be financially and economically viable, depending on the parameters that are selected. However, , the network architecture adopted in the mobile backhaul and its energy consumption, directly influence the profitability of the MNO. By including the network architectures examined in this study, it is striking that the Femto-CB has a high rate of profitability, whereas the Femto-BB has a low rate.

Figure 7 shows the annual amount of $\mathrm{CO}_{2}$ gas emissions that can be prevented by the users (kg/user/year), if they use the photovoltaic collection system. The main parameter is that of $\mathrm{CO}_{2}$ emissions where the estimate is made on the basis of a value of $0.1 \mathrm{~kg} / \mathrm{kWh}$, which is compatible with countries that have an energy matrix similar to that of Brazil (i.e., based mainly on the use of hydroelectric power). The volume of $\mathrm{CO}_{2}$ gas emissions that is prevented depends on the amount of electricity available from the supplier that ceases to be consumed, owing to the existence of the photovoltaic system. It should be noted that it is the Macro+Femto-CB architecture that ceases to release more emissions of $\mathrm{CO}_{2}$ into the atmosphere since its energy consumption is higher than that of other architectures and corresponds to approximately $60.0 \mathrm{~kg} / \mathrm{user} /$ year. . Subsequently, there were the Macro+DRABF, Macro+DRA-CF and ultimately Macro+Femto-BB architectures, the last of these containing features that had a low environmental impact.

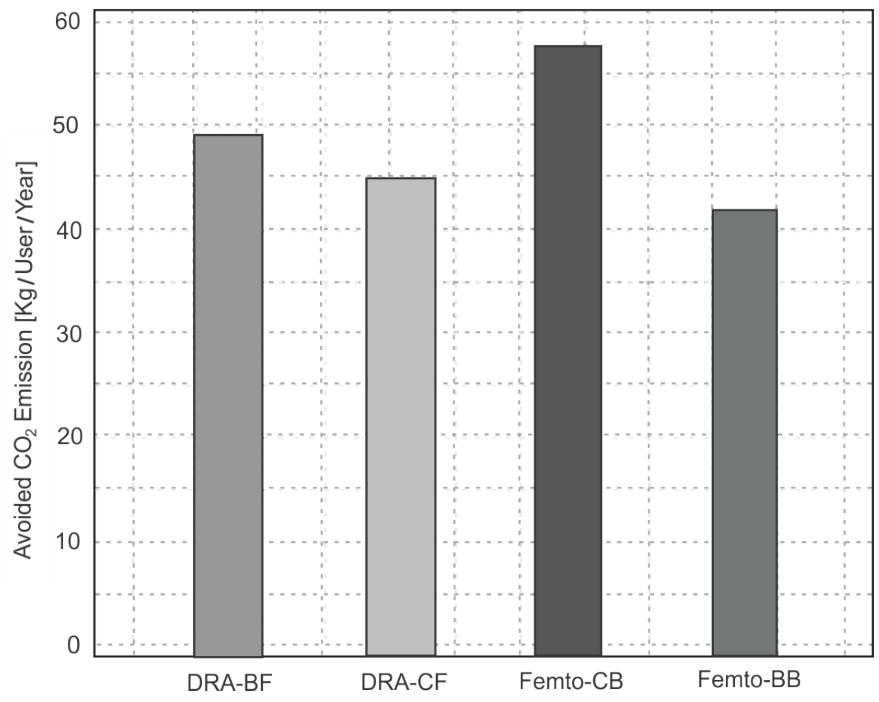

Fig. 7. Amount of $\mathrm{CO}_{2}$ gas emissions avoided by users each year.

By considering Figure 7 and using Equations (7) e (8), its possible to estimate the projections of deforestation associated with the volume of GHG avoided by each mobile architecture. Thus, the average avoided deforested area can be estimated at 6.49 (ha), 5.84 (ha), 7.14 (ha) and 5.45 (ha) for DRA-BF, DRA-CF, Femto-CB and Femto-BB architectures, respectively. It is important to highlight that these estimates are related to a simulated area of $1.0 \mathrm{~km}^{2}$, characterized with low $\mathrm{CO}_{2}$ emission factors $\left(0.1 \mathrm{kgCO}_{2} / \mathrm{kWh}\right)$. For instance, considering the geographical area of an ordinary European city, such as Amsterdam (219.32 $\left.\mathrm{km}^{2}\right)$, this estimates are projected at 1424.15 (ha), 1281.74 (ha), 1566.57 (ha) and 1196.29 (ha) for DRA-BF, DRA-CF, Femto-CB and Femto-BB architectures, respectively. Considering the case of Femto-CB architecture, the avoided deforestation is equivalent to $3.74 \%$ of the territory of the Netherlands.

\section{B. Sensitivity Analysis}

This section conducted a sensitivity analysis of the photovoltaic $T C O$ to validate the results obtained. An assessment was made by considering a variation in the main cost parameters, which range from $-30 \%$ to $30 \%$, and affect the total acquisition cost of the photovoltaic collection system. Also, this sensitivity analysis did not take account of the alternative technologies based on photovoltaic equipment or the use of alternative polycrystalline silicon technology because apart from the inherent variations in the value of this equipment, data such as nominal power efficiency, warranty time limit and the time when the useful life would be altered, made the analytical procedure more complex.

For all sensibility analysis scenarios, the following parameters was considered fixed $\rho=3,000$ users $/ \mathrm{km}^{2}, t_{s}=$ $6.0 \mathrm{~h}$ and $\gamma_{s}=5.5 \mathrm{kWh} / \mathrm{m}^{2}$.day. Hence, the first parameter assessed through sensibility analysis was the unit cost of the photovoltaic panels, which had a direct influence on the composition of $C A P E X$, since this is the main equipment used for the photovoltaic collection system and has the largest amount of right-sized equipment.

Thus, as shown in Figure 8 , the fact that there is a variation of 70.0 to $130.0 \%$ of the unit costs of the photovoltaic panels, suggests there is a considerable variation. In the case of the Macro+Femto-CB architecture, the TCO underwent a variation of approximately $20.0 \%$ ( $\$ 100,000,000.00)$, which even in the worst-case scenario (approximately $\mathrm{R} \$ 565$ million Reais), would still be lower than the reference value of $\mathrm{R} \$$ 591.72 million Reais for the cost of electricity from the supplier, as specified in Table II. The other architectures show the same range of variation $(20.0 \%)$, as well as having the TCO below the cost value shown in Table II, even when taking account of a price of $30.0 \%$.

Besides, another parameter that was considered was the rental costs per $\mathrm{m}^{2}$ of the roofs of the buildings designed for the installation of the solar collector panels, as shown in Figure 9. This variation was included because there is a wide range of values for the rental price per $\mathrm{m}^{2}$, even in the case of the rooftops, as found in the Brazilian real estate market, for example. Also, Fig. 9 reveals the variation experienced by the Macro+Femto-CB architecture, which was approximately $45 \%(\mathrm{R} \$ 190,000,000.00)$. However, in this case, according to the values set out in Table II, it was found that the limits to variations in the rental price of $\mathrm{m}^{2}$ of the roofs are approximately $25 \%$. The reason for this is that based on this value, the financial cost of electricity originating from 


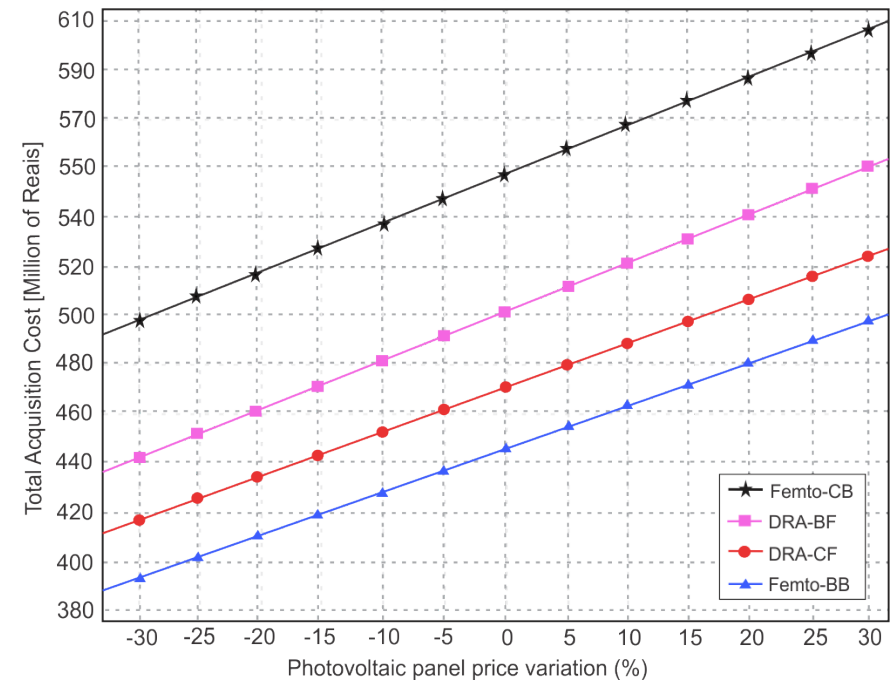

Fig. 8. Total Acquisition Costs resulting from variations in the price of the photovoltaic panels.

the supplier begins to be more advantageous concerning the use of the photovoltaic collection system because the rental expenses experience variations above what is expected by the investors.

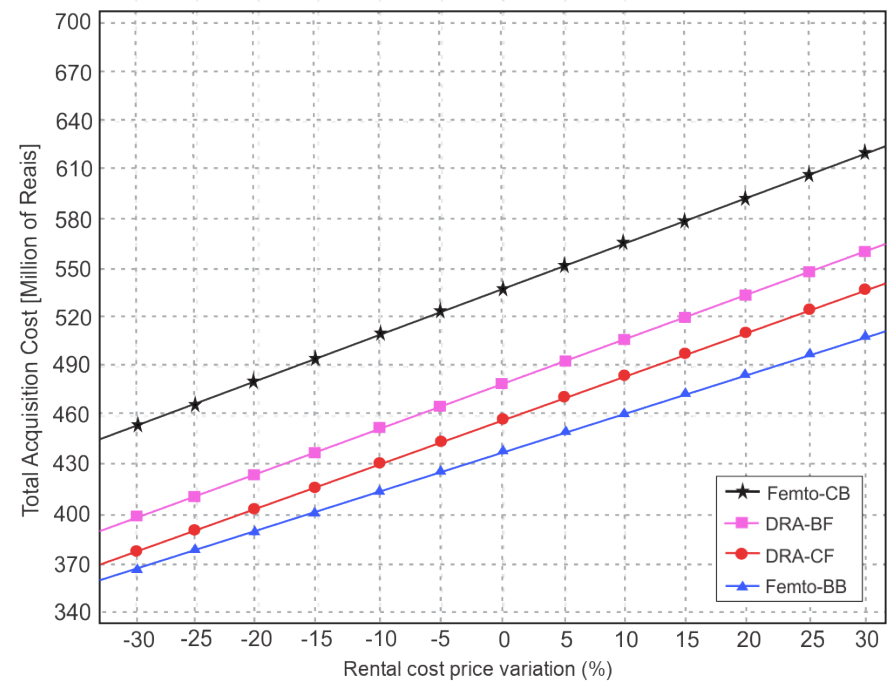

Fig. 9. Total Acquisition Cost resulting from variations in rental costs.

Concerning the Macro+DRA-BF architecture, this increased value of a neighboring region is approximately $20 \%$, while it is $15 \%$ and $10 \%$ for the Macro+DRA-CF and Macro+Femto-BB architectures, respectively. If one relies on this scale of values for the consumption of energy of each of the architectures, the Macro+Femto-CB architecture has the highest energy consumption, followed by the Macro+DRA-BF, Macro+DRA$\mathrm{CF}$ and Macro+Femto-BB architectures in that order. Thus, the increase in the rental price has a strong effect on the architectures which tend to consume less energy and conversely, on the architectures that consume more energy.

\section{CONCLUSION}

This study recommends the use of photovoltaic solar energy collection systems for generating energy in the HetNets and mobile backhaul infrastructure. Technical, economic and sustainable analyses were conducted to validate their feasibility. The results show that the use of photovoltaic collector systems is a promising alternative for the energy efficiency of heterogeneous mobile networks. Moreover, the total acquisition cost of the photovoltaic system is lower than an alternative energy costing strategy based on the conventional electricity network and suggests there are some financial benefits from adopting this structure. Also, the volume of $\mathrm{CO}_{2}$ gas emissions that can be avoided represents a significant reduction which is an endorsement of these systems in the context of mobile networks devoted to tackling current environmental issues.

A sensitivity analysis was conducted with the aim of determining the main cost factors and validating the proposed model. It was noted that the photovoltaic $T C O$ is more sensitive to price variations with regard to the photovoltaic panels and the rental costs $m^{2}$. In the case of the architectures analyzed, the variation in the price of the panels, did not influence the financial viability of the photovoltaic TCO, even when the least profitable scenarios were considered. In light of this, benefits were substantiated that go far beyond the sustainable development of the mobile operators, such as those of both an economic and social kind. Also, the results demonstrate in mathematical terms, that the use of renewable energy is a promising trend that can assist the operators and reduce the inevitable costs that OPEX involves, and above all, ensure environmental sustainability.

Finally, in future studies, we plan to extend the scope of this work by taking account of uncertainty with regard to the availability of solar light. This will entail factors such as climate, the particular region of the world or season of the year, as well as environmental temperature, that have a strong influence on the generation of energy. In addition, we seek to assess the impact of the space-time variations of the users when faced with the energy demands of heterogeneous network architectures and hence the influence of sizing the photovoltaic collector system. Finally, an attempt will be made to include other kinds of hybrid energy generation, factors such as opportunity costs, interest rates, or inflation to plan the monetary variation of the equipment and services covered in this study, in a more realistic way.

\section{REFERENCES}

[1] CISCO, Cisco Visual Networking Index Global Mobile Data Traffic Forecast Update 20162021 White Paper, Tech. rep., CISCO (2017).

[2] J. An, K. Yang, J. Wu, N. Ye, S. Guo, Z. Liao, Achieving Sustainable Ultra-Dense Heterogeneous Networks for 5G, IEEE Communications Magazine 55 (12) (2017) 84-90 (Dec 2017). doi:10.1109/MCOM. 2017.1700410

[3] 3GPP, Scenarios and Requirements for Small Cell Enhancements for E-UTRA and E-UTRAN, TR 36.932 v13.0.0, Tech. rep., 3GPP (2015).

[4] ITU-D, Quality of Service Regulation Manual International Telecommunication Union, Geneva, Switzerland, 2017 (2017). URL http://handle.itu.int/11.1002/pub/8108e11f-en

[5] F. Yaghoubi, M. Mahloo, L. Wosinska, P. Monti, F. d. S. Farias, J. C. W. A. Costa, J. Chen, A Techno-Economic Framework for 5G Transport Networks, IEEE Wireless Communications 25 (5) (2018) 5663 (October 2018). doi:10.1109/MWC.2018.1700233 
[6] BP, BP Statistical Review of World Energy 2019-68th Edition (2019). doi:10.2307/3324639

[7] M. H. Alsharif, Comparative Analysis of Solar-Powered Base Stations for Green Mobile Networks, Energies 10 (2017) 1208 (2017). doi: $10.3390 / \mathrm{en} 10081208$

[8] F. Ahmed, M. Naeem, M. Iqbal, ICT and renewable energy: a way forward to the next generation telecom base stations, Telecommunication Systems 64 (1) (2017) 43-56 (jan 2017). doi:10.1007/s11235016-0156-4

[9] D. Li, P. Deng, Y. Xu, L. Gao, G. Zhang, Joint access spectrum and backhaul energy allocation for green cognitive heterogeneous networks, IEEE Access 6 (2018) 24793-24808 (2018). doi:10.1109/ACCESS. 2018.2794520

[10] D. Li, L. Gao, X. Sun, F. Hou, S. Gong, A cellular backhaul virtualization market design for green small-cell networks, IEEE Transactions on Green Communications and Networking 3 (2) (2019) 468-482 (June 2019). doi:10.1109/TGCN.2019.2904975

[11] R. Yadav, W. Zhang, MeReg: Managing Energy-SLA Tradeoff for Green Mobile Cloud Computing, Wireless Communications and Mobile Computing 2017 (2017) 11 (2017). doi:10.1155/2017/6741972

[12] M. Demirtaş, A. Soysal, Nonoverlay Heterogeneous Network Planning for Energy Efficiency, Wireless Communications and Mobile Computing 2017 (2017) 11 (2017). doi:10.1155/2017/6519709

[13] Wen-Cheng Lu, The impacts of information and communication technology, energy consumption, financial development, and economic growth on carbon dioxide emissions in 12 asian countries, Mitigation and Adaptation Strategies for Global Change 23 (8) (2018) 1351-1365 (Dec 2018). doi:10.1007/s11027-018-9787-y

[14] G. Fagas, L. Gammaitoni, J. Gallagher, D. Paul, ICT - Energy Concepts for Energy Efficiency and Sustainability, IntechOpen, 2017 (2017). doi: $10.5772 / 62522$

[15] F. Shabnam, Analysis of energy harvesting techniques for mobile networks, in: 2019 IEEE Region 10 Symposium (TENSYMP), 2019, pp. 784-788 (June 2019). doi:10.1109/TENSYMP 46218.2019. 8971237

[16] Z. Chang, C. Jing, X. Guo, Z. Han, T. Ristaniemi, Resource allocation for wireless virtualized hetnet with caching and hybrid energy supply, in: 2018 IEEE Wireless Communications and Networking Conference (WCNC), IEEE, Barcelona, Spain, 2018, pp. 1-6 (April 2018). doi : $10.1109 /$ WCNC.2018.8377258

[17] F. Shi, K. Sun, W. Huang, Y. Wei, User Association for on-grid Energy Minimizing in HetNets with Hybrid Energy Supplies, in: 2018 IEEE 18th International Conference on Communication Technology (ICCT), IEEE, Chongqing, China, 2018, pp. 778-783 (Oct 2018). doi:10. 1109/ICCT.2018.8600150

[18] R. Zhang, Y. Li, C. Wang, Y. Ruan, Y. Fu, H. Zhang, Energy-Spectral Efficiency Trade-Off in Underlaying Mobile D2D Communications: An Economic Efficiency Perspective, IEEE Transactions on Wireless Communications 17 (7) (2018) 4288-4301 (July 2018). doi:10. $1109 /$ TWC.2018.2822284

[19] Y. Luo, Z. Shi, F. Bu, J. Xiong, Joint optimization of area spectral efficiency and energy efficiency for two-tier heterogeneous ultra-dense networks, IEEE Access 7 (2019) 12073-12086 (2019). doi:10. $1109 /$ ACCESS .2019.2891551

[20] M. W. Baidas, M. Al-Mubarak, E. Alsusa, M. K. Awad, Joint subcarrier assignment and global energy-efficient power allocation for energyharvesting two-tier downlink noma hetnets, IEEE Access 7 (2019) 163556-163577 (2019). doi:10.1109/ACCESS.2019.2952293

[21] M. A. Abu-Rgheff, 5G Enabling Technologies: Network Virtualization and Wireless Energy Harvesting, John Wiley \& Sons, Ltd, 2019, Ch. 3, pp. 99-149 (2019). doi:10.1002/9781119525547.ch3

[22] M. Ozger, O. Cetinkaya, O. B. Akan, Energy harvesting cognitive radio networking for iot-enabled smart grid, Mobile Networks and Applications 23 (4) (2018) 956-966 (Aug 2018). doi:10.1007/s11036017-0961-3

[23] K. B. Letaief, W. Chen, Y. Shi, J. Zhang, Y. A. Zhang, The Roadmap to 6G: AI Empowered Wireless Networks, IEEE Communications Magazine 57 (8) (2019) 84-90 (August 2019). doi:10.1109/MCOM. 2019.1900271

[24] W. Saad, M. Bennis, M. Chen, A Vision of 6G Wireless Systems: Applications, Trends, Technologies, and Open Research Problems, IEEE Network (2019) 1-9 (2019). doi:10.1109/MNET.001.1900287

[25] J. Malmodin, D. Lundén, The Energy and Carbon Footprint of the Global ICT and E\&M Sectors 2010-2015, Sustainability 10 (9) (2018). doi: $10.3390 / \mathrm{su} 10093027$

[26] F. Amri, Carbon dioxide emissions, total factor productivity, ict, trade, financial development, and energy consumption: testing environmen- tal kuznets curve hypothesis for tunisia, Environmental Science and Pollution Research 25 (33) (2018) 33691-33701 (Nov 2018). doi: $10.1007 / \mathrm{s} 11356-018-3331-1$

[27] A. Z. Aktas, Could energy hamper future developments in information and communication technologies (ict) and knowledge engineering?, Renewable and Sustainable Energy Reviews 82 (2018) 2613 - 2617 (2018). doi:10.1016/j.rser.2017.09.087

[28] IHS Markit, Predictions for the PV industry in 2019, Tech. rep., IHS Markit, London, UK, https://ihsmarkit.com/products/downstreampv-intelligence-service.html (2018).

[29] IEA, Tracking power, Tech. rep., IEA, Paris, https://www.iea.org/reports/ tracking-power-2019 (2019).

[30] L. Tian, J. Pan, R. Du, W. Li, Z. Zhen, G. Qibing, The valuation of photovoltaic power generation under carbon market linkage based on real options, Applied Energy 201 (2017) 354-362 (2017). doi:10. $1016 / j$.apenergy.2016.12.092

[31] E. Vartiainen, G. Masson, C. Breyer, D. Moser, E. Román Medina, Impact of weighted average cost of capital, capital expenditure, and other parameters on future utility-scale pv levelised cost of electricity, Progress in Photovoltaics: Research and Applications n/a (n/a) (2019) 1-15 (2019). doi:10.1002/pip.3189

[32] M. A. De Souza, F. S. Farias, J. C. Costa, D. L. Cardoso, Technical Economic Analysis of Photovoltaic Systems in Heterogeneous Mobile Networks, in: Procedia Computer Science, 2017, pp. 825-832 (2017). doi:10.1016/j.procs.2017.05.346

[33] F. Ahmed, N. Muhammad, W. Ejaz, M. Iqbal, H. Kim, Renewable energy assisted traffic aware cellular base station energy cooperation, Energies 11 (2018) 99 (01 2018). doi:10.3390/en11010099

[34] Y. Zhang, M. Meo, R. Gerboni, M. Ajmone Marsan, Minimum cost solar power systems for LTE macro base stations, Computer Networks 112 (2017) 12-23 (2017). doi:10.1016/j.comnet.2016.10.008

[35] L. Huo, D. Jiang, Stackelberg Game-based Energy-Efficient Resource Allocation for 5G Cellular Networks, Telecommunication Systems 72 (3) (2019) 377-388 (Nov 2019). doi:10.1007/s11235-019$00564-\mathrm{w}$

[36] M. Feng, S. Mao, T. Jiang, Base station on-off switching in $5 \mathrm{~g}$ wireless networks: Approaches and challenges, IEEE Wireless Communications 24 (4) (2017) 46-54 (Aug 2017). doi:10.1109/MWC.2017. 1600353

[37] M. Fiorani, S. Tombaz, F. S. Farias, L. Wosinska, P. Monti, Joint Design of Radio and Transport for Green Residential Access Networks, IEEE Journal on Selected Areas in Communications 34 (4) (2016) 812-822 (2016). doi:10.1109/JSAC.2016.2544599

[38] T. Pamuklu, C. Ersoy, Reducing the total cost of ownership in radio access networks by using renewable energy resources, Wireless Networks (2018). doi:10.1007/s11276-018-1862-5

[39] B. A. Aderemi, S. P. D. Chowdhury, T. O. Olwal, A. M. Abu-Mahfouz, Techno-Economic Feasibility of Hybrid Solar Photovoltaic and Battery Energy Storage Power System for a Mobile Cellular Base Station in Soshanguve, South Africa, Energies 11 (6) (2018). doi:10.3390/ en11061572

[40] D. Renga, M. Meo, Dimensioning Renewable Energy Systems to Power Mobile Networks, IEEE Transactions on Green Communications and Networking 3 (2) (2019) 366-380 (June 2019). doi : 10 . 1109/TGCN. 2019.2892200

[41] Y. Zhang, M. Meo, R. Gerboni, M. A. Marsan, Minimum cost solar power systems for LTE macro base stations, Computer Networks 112 (2017) 12 - 23 (2017). doi:10.1016/j.comnet.2016.10.008

[42] N. M. Kumar, M. S. P. Subathra, J. E. Moses, On-grid solar photovoltaic system: Components, design considerations, and case study, in: 2018 4th International Conference on Electrical Energy Systems (ICEES), 2018, pp. 616-619 (Feb 2018). doi:10.1109/ICEES.2018.8442403

[43] A. Bouaichi, A. E. Amrani, M. Ouhadou, A. Lfakir, C. Messaoudi, Insitu performance and degradation of three different photovoltaic module technologies installed in arid climate of morocco, Energy 190 (2020) 116368 (2020). doi:10.1016/j.energy.2019.116368

[44] Department for Bussiness, Energy \& Industrial Strategy, 2018 Government GHG Conversion Factors for Company Reporting: Methodology paper for emission factors - Final Report, Tech. rep., BEIS, London, UK (2018).

[45] P. R. Shukla, et al., Technical Summary: Climate Change and Land: an IPCC special report on climate change, desertification, land degradation, sustainable land management, food security, and greenhouse gas fluxes in terrestrial ecosystems, IPCC, 2019 (2019). doi:10.4337/ 9781784710644

[46] Federative Republic of Brazil, Decree No. 7,390/2010: Regulates arts. 6, 11 and 12 of Law No. 12.187, of December 29, 2009, which establishes 
the National Policy on Climate Change - PNMC, and other measures (2010).

[47] N. Panwar, S. Sharma, A. K. Singh, A survey on 5G: The next generation of mobile communication, Physical Communication 18 (2016) 64-84 (2016). arXiv:1511.01643 doi:10.1016/j.phycom.2015. 10.006

[48] Canadian Solar, 50/60kW three phase inverters. CSI-50KTL-GIHFL Model datasheet, https://www.canadiansolar.com/inverter-forcommercial/ (2020).

[49] Canadian Solar, Quarteck MaxPower CS6X-320P 320W Data Sheet, https://www.canadiansolar.com/module/ (2020).

[50] Neosolar Energy, Thesan Photovoltaic Roof Mounting Kit, https://www. neosolar.com.br/ (2020).

[51] E. B. Pereira, et al., Brazilian Atlas of Solar Energy, 2nd Edition, INPE, São José dos Campos, 2017, http://urlib.net/rep/8JMKD3MGP3W34P/ 3PERDJE (2017).

[52] X. Zhang, H. Zhang, C. Zhao, J. Yuan, Carbon emission intensity of electricity generation in belt and road initiative countries: a benchmarking analysis, Environmental Science and Pollution Research 26 (15) (2019) 15057-15068 (May 2019). doi:10.1007/s11356-019-048605

[53] R. Fu, et al., National Renewable Energy Laboratory - U.S. Solar Photovoltaic System Cost Benchmark Q1 2018 Report, Tech. rep., NREL (2018). doi:10.7799/1503848

[54] FIPE, Commented Indexes: Fipezap Index - Real Estate Price Index Advertised for Residential Rental, https://www.fipe.org.br/pt-br/ publicacoes/relatorios/\#relatorio-fipezap (2018).

[55] R. Nakabayashi, Photovoltaic Micro-generation in Brazil: Current Conditions and Future Prospects, Master thesis, Institute of Energy and Environment. Graduate Program In Energy. University of Sao Paulo (2014). doi:10.11606/D.106.2014.tde-26012015-141237

[56] I. Mauleón, Photovoltaic investment roadmaps and sustainable development, Journal of Cleaner Production 167 (2017) 1112 - 1121 (2017). doi:10.1016/j.jclepro.2017.08.148

[57] ANEEL, Brazilian National Ranking of Energetic Tariffs, https://www. aneel.gov.br/ranking-das-tarifas (2018).

[58] ANEEL, Normative Resolution n. 414/2010, September 9th, 2010, http: |//www2.aneel.gov.br/cedoc/bren2010414.pdf (2010).

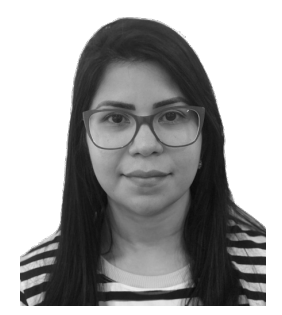

Marcela Alves de Souza received a B.S. in information systems in 2012 from the Federal University of Pará (UFPA), Marabá, Brazil, and an M.S. in electrical engineering with emphasis on applied computing in 2016 from the UFPA, Belém, Brazil, where she is currently pursuing a Ph.D. Since 2014, she has been an information technology analyst at the Information and Communication Technology Center with Unifesspa. She has experience in information systems, software analysis, and development, process modeling, database administration, and programming languages. Her research interests include energy efficiency, wireless mobile networks, energy harvesting, and technoeconomic analysis.

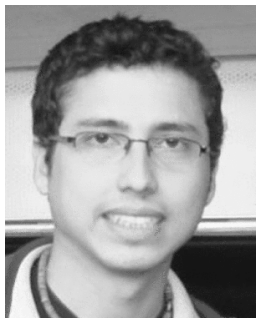

Fabricio Souza Farias received an M.S. and a Ph.D. in electrical engineering from the Federal University of Pará - UFPA, in 2012 and 2016, respectively. He received the bachelor's degree in computer engineering from the UFPA in 2010. He is professor with the CUTINS at the UFPA and he is the head of the Extreme Programming Laboratory (LABEX) since 2014.

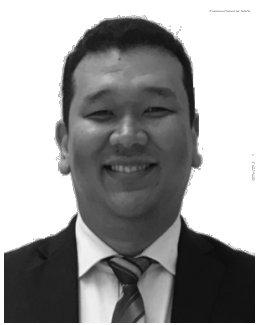

Hugo Pereira Kuribayashi received a B.S. and an M.S. in computer science from the Federal University of Pará (UFPA), Belém, Brazil, in 2007 and 2011, respectively. Currently, he is pursuing a Ph.D. in electrical engineering with an emphasis on applied computing from the UFPA. Additionally, he is an assistant professor with the Faculty of Computing and Electrical Engineering at the Federal University of South and Southeast Pará (Unifesspa). At Unifesspa, from 2013 to 2017, he was the Director of the Information and Communication Technology Center, and from 2017 to 2019, he was the Pro-rector of Administration. His research interests are next-generation networks, energy efficiency, smart radio resource management for wireless mobile networks, and the Internet of Things.

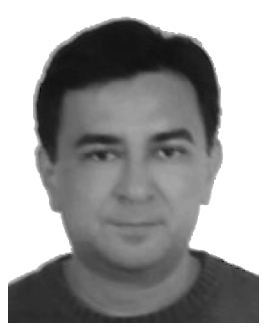

Carlos Renato Lisbôa Francês received a B.S. in computer science from the Federal University of Pará (UFPA) in 1995, and an M.S. and a Ph.D. from the University of São Paulo, Brazil, in 1998 and 2001, respectively. He held a postdoctoral position with the Institute for Systems and Computer Engineering, Technology and Science, Porto, Portugal, in 2012. He is currently an associate professor with the Telecommunication and Computer Engineering Department, UFPA. His research interests include performance evaluation, optimization, Markov processes, and artificial intelligence models.

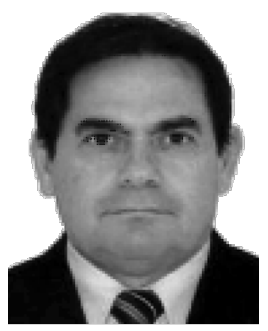

João C. Weyl Albuquerque Costa (S'94-M'95) received a B.Sc. in electrical engineering from the Federal University of Pará (UFPA), Belém, Brazil, in 1981, an M.Sc. in electrical engineering from the Pontifical Catholic University of Rio de Janeiro, Rio de Janeiro, Brazil, in 1989, and a Ph.D. in electrical engineering from the State University of Campinas, Campinas, Brazil, in 1994. He is currently a professor with the Institute of Technology, UFPA, and a researcher with the Brazilian Research Funding Agency National Council for Scientific and Technological Development, Brasília, Brazil. His current research interests include broadband systems and optical sensors.

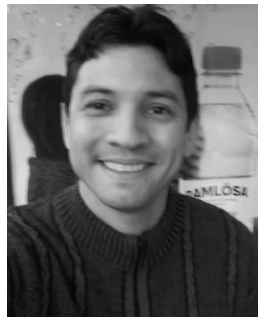

Diego Lisboa Cardoso received the bachelor's degree in computer science from the University of Amazonia, in 2002, the master's and Ph.D. degrees in electrical engineering from the Federal University of Pará, in 2005 and 2010, respectively, and the Ph.D. degree from the Royal Institute of Technology of Sweden (KTH).,He is an Associate Professor of the Graduate Program in Electrical Engineering (PPGEE) with the Faculty of Computer Engineering and Telecommunications, Federal University of Pará. He has experience in computer science and computer engineering, focusing on performance evaluation, acting on the following subjects such as digital TV, access technologies, Markov and simulation performance models, applied computational intelligence, and optimization techniques. Dr. Cardoso is an Associate Member of the Brazilian Computer Society (SBC). 